\title{
IMPLEMENTASI ASTANGGA YOGA \\ SEBAGAI PENGUATAN PENDIDIKAN KARAKTER \\ DI SMP NASIONAL DENPASAR
}

Oleh:

I Komang John Purnawan

\begin{abstract}
:
The education of character's building is a rising brand new innovation to incrase moral degradation who are facing by teenagers now adays. Spiritual and mental adding value are very necessary to support the process of character's building education. The education process which concentrates in its spiritual and mentality has been found in the concept of Hinduism called the teachings of Yoga Specifically, it is about concept Astangga Yoga such as: yama =control, nyama=morality, asana=body posture, pranayama $=$ breathe management, pratyahara $=$ sensual with drawal, dharana $=$ attention, dhyana $=$ meditation, sadism $=$ concentration. At Denpasar Nasional Middle School, they have carried out the teaching process of Astangga yoga as a reinforcement of character education. The existence of ekstrakulikular Yoga as a stage of phsycal training for student/student and the process of concentration and control of emotions (emotions), has been carried out at the beginning of the learning process in the classroom during the study of Hinduism dab Manners.
\end{abstract}

Keyword: Astangga Yoga, Character Education

\section{ABSTRAK:}

Pendidikan karakter merupakan sebuah inovasi baru yang muncul untuk mengurangi degradasi moral yang dialami oleh remaja sekarang ini. Penanaman nilai spiritual dan mental menjadi sangat penting untuk dapat mendukung proses pendidikan karakter tersebut. Proses pendidikan yang menitikberatkan pada spiritual dan mental tentunya terdapat dalam konsep agama Hindu yakni ajaran Yoga. Ajaran Yoga yang dimaksud adalah mengenai konsep pelaksanaan Astangga Yoga yang terdiri dari; yama = pengendalian, nyama $=$ sikap moral, asana $=$ sikap tubuh, pranayama $=$ pengaturan nafas, pratyahara $=$ penarikan indria-indria, dharana $=$ atensi, dhyana $=$ meditasi, Samadhi $=$ konsentrasi. Di SMP Nasional Denpasar sudah melaksanakan proses ajaran Astangga Yoga sebagai sebuah penguatan pendidikan karakter. Adanya Ekstrakulikuler Yoga sebagai sebuah tahapan latihan fisik bagi peserta didik/siswa, dan proses konsentrasi dan pengendalian diri (emosi), sudah dilaksanakan pada saat awal proses pembelajaran di kelas pada saat mata pelajaran agama Hindu dan Budi Pekerti.

Kata kunci: Pendidikan karakter, Astangga Yoga

\section{PENDAHULUAN}

Dewasa ini, seiring dengan perkembangan globalisasi dan modernisasi yang begitu pesat, memberikan sebuah implikasi dalam kehidupan sosial masyarakat baik nilai positif maupun nilai yang negatif terhadap pola pikir dari remaja dewasa ini. Dalam perkembangan jaman globalisasi dan modernisasi serta pesatnya perkembangan teknologi informasi dan komunikasi menyebabkan terjadinya degradasi moral dikalangan remaja pada masa kini (jaman now). Perilaku remaja masa kini lebih banyak mengarah dan menyimpang dari ajaran pendidikan khususnya pada ajaran agama. Seperti halnya, remaja saat ini terkadang tidak ada rasa hormat kepada lawan bicaranya, apakah yang diajak berbicara adalah orang yang lebih tua atau orang tua. Bahkan remaja sekarang ini jarang yang tahu bagaimana seharusnya mereka 
berprilaku yang baik, sopan, santun, dan hormat terhadap orang tua, guru dan orang yang lebih tua. Mereka bahkan tidak memiliki rasa malu terhadap orang lain sehingga mereka menganggap boleh berprilaku sesuai keinginan mereka karena tidak ada larangan.

Perkembangan selanjutnya, peran pemerintah memberikan suatu solusi bagi persoalan yang dihadapi oleh remaja pada dewasa ini, yakni dengan membuatkan sebuah konsep baru yang dikenal dengan sebutan pendidikan karakter. Pendidikan karakter berlandaskan pada apa yang dilihat oleh pemerintah terhadap objek yang dinilai yakni remaja pada umumnya. Penurunan atau degradasi moral yang sangat pesat menyebabkan ada hal yang harus diubah dalam setiap proses pembelajaran sekolah, sehingga muncullah program pendidikan karakter ini yang menitik beratkan agar para remaja selalu berprilaku atas dasar kebenaran yang sudah tertuang dalam ajaran agamanya. Pendidikan karakter ini secara umum dibagi menjadi delapan belas bagian yakni: religius, jujur, toleransi, disiplin, kerja keras, kreatif, mandiri, demokratis, rasa ingin tahu, semangat kebangsaan, cinta tanah air, menghargai prestasi, bersahabat/komunikatif, cinta damai, gemar membaca, peduli lingkungan, peduli sosial, dan tanggung jawab.

Pendidikan karakter dalam agama Hindu menitikberatkan pada pemahaman mental dan spiritual anak. Pemahaman spiritual atau mental ini, menitikberatkan pada perubahan pola pikir anak dan pengendalian emosi agar tidak terjerumus kepada hal-hal yang sifatnya negatif, maka dari itu, pendidikan spiritual dalam hal ini dapat dilaksanakan dengan metode pelatihan dasar Yoga yang menitik beratkan pada konsentrasi dan pengendalian diri pada anak, sehingga dapat terhindar dari hal-hal yang sifatnya negatif. Pemahamanajaran Yoga(Astangga Yoga), tentunya dapat diimplementasikan dalam setiap proses pembelajaran bagi anak-anak remaja disekolah. Yoga dalam hal ini merupakan gaya hidup, suatu sistem pendidikan yang terpadu antara tubuh, pikiran, dan jiwa (Widya, 2015: 6). Implementasi ajaran Astangga Yoga sudah berlangsung dalam proses pendidikan agama Hindu dan Budi Pekerti di SMP Nasional, baik pada saat proses belajar ataupun pada saat ekstrakulikuler Yoga itu sendiri.

\section{PEMBAHASAN}

\subsection{Pendidikan Karakter}

Pendidikan merupakan wahana pengubahan kepribadian dan pengembangan diri. Oleh karena itu, pendidikan juga memiliki dampak besar terhadap peningkatan kualitas dan perilaku hidup masyarakat. Dalam Undang-Undang RI No. 20 Tahun 2003 tentang sistem pendidikan nasional dijelaskan bahwa "Pendidikan nasional berfungsi mengembangkan kemampuan dan membentuk watak serta peradaban bangsa, bertujuan untuk berkembangnya potensi peserta didik agar menjadi manusia yang beriman dan bertaqwa kepada Tuhan Yang Maha Esa, berakhlak mulia, sehat, berilmu, cakap, kreatif, mandiri, dan menjadi warga Negara yang demokratis serta bertanggung jawab (Departemen Pendidikan RI, 2003: 8). Pendidikan berbasis karakter merupakan aspek yang sangat penting bagi generasi muda. Seorang individu tidak hanya cukup diberi bekal pembelajaran dalam segi moral dan spiritualnya. Pendidikan karakter harus diberi seiring dengan perkembangan intelektualnya yang dalam hal ini harus dimulai sejak dini khususnya dilembaga pendidikan. Pendidikan karakter di sekolah dapat dimulai dengan memberikan contoh yang dapat dijadikan teladan bagi murid dengan diiringi pemberian pembelajaran seperti keagamaan dan kewarganegaraan sehingga dapat membentuk individu yang berjiwa sosial, mengembangkan cita-cita luhur, mencintai dan menghormati orang lain, yang berkaitan dengan pelaksanaan ajaran Tat Twam Asi dan Vasudhaiva Kutumbakam.

Pembelajaran tentang konsep-konsep keagamaan, sejak dini (anak-anak) dapat diberikan sebagai upaya penguatan terhadap doktrin 
keagamaan sebagai metodelogi penanaman teologi (Donder, 2011: 73). Bhagawan Wararuci menguraikan bahwa usia anak-anak itu bagaikan ujung daun ilalang yang masih muda sebagai mana diuraikan dalam kitab suci Sarasamuccaya 27 sebagai berikut:

\begin{abstract}
Matangnya deyaning wwang, pêngpônganikang kayowanan panedeng ning awak, sādhanākena ri kārjananing dharma, artha, jñāna, kunang apan tan pada kasaktining atuha lawan rare, drștānta nahan yangalalang atuha, têlas rumêpa, marin alaṇdêp ika.
\end{abstract}

(Sarasamuccaya 27)

Terjemahannya:

Karenanya perilaku seseorang, hendaklah digunakan sebaik-baiknya semasih muda, selagi badan sedang kuat-kuatnya, hendaklah dipergunakan untuk usaha menuntut dharma, artha, dan ilmu pengetahuan, sebab tidak sama kekuatan orang tua dengan kekuatan anak muda, contohnya ialah seperti ilalang yang telah tua itu menjadi rebah, dan ujungnya itu tidak tajam lagi (Kajeng, 1997:25).

Pendidikan karakter bisa dikatakan sebagai sebuah usaha untuk menghidupkan spiritual yang ideal. Pendidikan karakter dapat dijadikan sebagai sebuah strategi untuk mengatasi pengalaman yang selalu berubah sehingga mampu membentuk identitas yang kokoh dari setiap individu, dalam hal ini dapat dilihat bahwa tujuan pendidikan karakter ialah mampu untuk membentuk sikap yang dapat membawa kearah kemajuan tanpa harus bertentangan dengan norma yang berlaku (Wikipedia.org). Pemahaman Pendidikan Karakter di SMP Nasional Denpasar tercermin dari Visi dari SMP Nasional Denpasar yakni "Terwujudnya Sekolah Unggul Dalam Taqwa, Berkarakter, Berbudaya, dan Berwawasan Lingkungan”. Pengembangan pendidikan karakter tertuang dalam salah satu misi dari SMP Nasional Denpasar yakni "Mengembangkan pembentukan karakter yang religius, santun, jujur, dan peduli terhadap lingkungan, melalui tindakan nyata di SMP Nasional Denpasar". Berdasarkan hal tersebut, maka Visi dan Misi dari SMP Nasional Denpasar tentunya sudah mengarah pada proses pendidikan karakter yang ingin dicapai oleh pemerintah.

\subsection{Konsep Ajaran Yoga}

Pendiri ajaran Yoga adalah Maha Rsi Patanjali. Karyanya yang terkenal adalah Patanjali Yoga Sutra. Kata Yoga dalam bahasa Sanskerta berasal dari akar kata "yuj” yang artinya bersatu/ menyatu. Maha rsi Patanjali dalam karyanya mengartikan yoga bukan sebagai penyatuan, tetapi upaya spiritual untuk mencapai kesempurnaan melalui pengendalian tubuh, indria, pikiran dan melalui diskriminasi yang benar antara purusa dan prakerti.

Yoga Sutra sebagai karya besar Patanjali merupakan buku teks yang mengkaitkan beberapa teknik meditasi yoga. Yoga Sutra pada umumnya dibagi dalam empat bagian yakni: konsentrasi (Samadhi), praktek (sadhana), penguatan (empower ment) dan isolasi (kaivalya). Manfaat yoga sebagaimana diuraikan Patanjali adalah sebuah diskusi mengenai kekuatan yang tumbuh selama mempraktekkan yoga, yang merupakan pengembaraan yang menarik dalam pemikiran Patanjali. Sistem yoga memberikan metode tentang proses pengembangan kesadaran individu menuju kesadaran universal, oleh karena itu, sistem yoga merupakan pembudayaan manusia yang seutuhnya.

Sistem yoga ini, menurut Patanjali disebut dengan Raja Yoga yang didefinisikan sebagai penghilangan total dari modifikasi citta. Penghentian ini dilakukan melalui meditasi dan konsentrasi disebut yoga samadhi. Konsep yoga dilakukan dengan metode penghentian fungsifungsi mental (citta vrtti nirodha). Citta atau intelek, ahamkara atau ego, dan manas atau pikiran. Citta adalah evolusi pertama dari prakerti dan mempunyai dominasi sattva, tidak berkesadaran, sangat halus dan dekat dengan purusa, oleh karenanya nampak seperti memiliki kesadaran. Ketika berhubungan dengan objek, maka ia 
akan mengasumsikan "bentuk" objek tersebut. Pengaplikasian ini disebut vrtti atau modifikasi atau fluktuasi. Citta memiliki lima tingkatan:

1. Ksipta: kondisi pikiran yang buyar tidak menentu, pikiran terseret diantara objekobjek.

2. Mudha Viksipa: ada dalam kondisi yang serupa

3. Viksipta: kondisi secara relatif ditenangkan, yoga tidak mungkin dapat diwujudkan dalam kondisi seperti diatas.

4. Ekagra: suatu keadaan konsentrasi pikiran atas objek kontemplasi.

5. Niruddha: penghilangan bahkan aktifitas atau fungsi kontemplasi (Seregig, 2012: 97-98).

Sistem yoga bertujuan untuk menghasilkan suatu keadaan mental yang disebut dengan "rtambhara prajna", bukan untuk menghasilkan kecerdasan luar biasa, juga bukan untuk menghasilkan seseorang yang memiliki ingatan menakjubkan atau seseorang yang ulung dalam suatu keahlian atau memiliki kesaktian, tetapi merupakan suatu sistem untuk mengatur kecenderungan-kecenderungan citta (alam pikiran).

Citta diibaratkan sebuat kolam, airnya tenang dan tiada gerakan atau aktifitas sedikitpun, tetapi segera berubah dan terpengaruh oleh suatu hal yang sepele, sebuah batu kecil yang dilemparkan ke kolam tersebut, pasti akan menimbulkan riakriak dan mengganggu ketenangan citta, jadi citta dapat dipengaruhi oleh lingkungannya. Akibat dari pengaruh lingkungan itulah dapat menimbulkan goncangan-goncangan yang mungkin sangat hebat dan pasti mengalami pasang surut, namun untuk mengembalikan ketenangan sepenuhnya air kolam itu, pasti harus dapat menghilangkan aktifitas yang mempengaruhi air kolam tersebut. Pengembalian ketenangan air kolam itulah diibaratkan sebagai proses pendakian menuju suatu kondisi mental (Samadhi), sedangkan riak-riak berupa kisarankisaran yang timbul sebagai efek batu kecil yang dilemparkan ke kolam itu, sehingga menimbulkan suatu gerakan atau arus dengan kecepatan tertentu yang berbeda-beda, hal ini disebut dengan Vrtti (sanskerta), dengan kata lain bahwa Vrtti adalah suatu gelombang penalaran dalam pikiran yang berkisar disekitar sesuatu hal yang membawa seseorang dalam keadaan goncang sampai ia dapat mengatasi kembali goncangan yang dihadapinya, diibaratkan sebagai proses menenangkan kembali pusaran-pusaran air yang terjadi akibat batu kecil yang dilemparkan ke kolam itu.

Kisaran tersebut diatas, sifatnya bukan sebagai aktifitas mental yang timbul dan hilang, melainkan sebagai peristiwa istimewa yang sedemikian rupa, sehingga setelah aktifitas berhenti tinggalah akibat-akibatnya, berupa: kisaran ajaib yang ditinggalkan dan bilamana tidak diambil suatu tindakan, maka akibatnya sangat merugikan. Menentramkan kisaran-kisaran pikiran itu adalah yoga, dengan kata lain yoga adalah pengendalian fungsi-fungsi pikiran.

\subsection{Astangga Yoga sebagai Penguatan Pendidikan Karakter}

Ajaran yoga adalah sistem filsafat yang benar-benar sangat praktis, pembahasannya hanya berkisar pada hakikat pikiran, gangguangangguannya dan metode untuk mencapai tujuan hidup tertinggi yang disebut dengan realisasi diri atau kaivalya. Metode yang diterapkan dalam ajaran ini adalah delapan sikap perilaku diri yang harus dipraktekkan dalam kehidupan para penganut ajaran yoga. Kedelapan sikap perilaku diri ini disebut dengan Astangga Yoga.

Tahapan-tahapan yang harus dilalui para penganut ajaran yoga adalah; yama=pengendalian, nyama $=$ sikap moral, asana $=$ sikap tubuh, pranayama $=$ pengaturan nafas, pratyahara $=$ penarikan 
indria-indria, dharana=atensi, dhyana $=$ meditasi, samadhi=konsentrasi. Yama dan Nyama merupakan konsep dasar Etika dalam yoga yang menitikberatkan pada sebuah pengendalian diri dan juga sikap moral yang erat kaitannya dengan pendidikan karakter (Seregig, 2012: 98). Adapun penjelasannya sebagai berikut:

1. Yama artinya tidak melaksanakan tindakan yang menyakiti kehidupan, antara lain tidak bertindak salah, tidak mencuri, dapat mengendalikan hawa nafsu, dan tidak tamak. Konsep Yama dalam hal ini erat kaitannya dengan ajaran Panca Yama Brata yang terdiri dari:

a. Ahimsa: tanpa kekerasan adalah tidak melukai makhluk lain manapun dalam pikiran, perkataan, dan perbuatan (Tri Kaya Parisudha).

b. Satya: kebenaran dalam pikiran, perkataan, dan perbuatan.

c. Asteya: tidak menginginkan barang milik orang lain/tidak mencuri.

d. Brahmacarya: pantang dalam kenikmatan sosial.

e. Aparigraha: pantang kemewahan, dan tidak banyak kemauan.

2. Nyama artinya menggali kebiasaan-kebiasaan baik yaitu: pola hidup suci, kegembiraan, dan belajar Veda. Ajaran Yama tertuang dalam konsep Panca Nyama Brata yang terdiri dari:

a. Sauca: bersih lahir bathin,

b. Santosa: kepuasan. Melaksanakan kebaikan atau kebajikan menghantarkan kepada kesenangan yang tidak terkatakan.

c. Tapa: pantangan. Tapa menghasilkan pemenuhan semua kebutuhan badan dan alat-alatnya, melalui kesengsaraan dan pantangan, badan menjadi kuat dan bebas dari noda-noda. d. Swadhyaya: mempelajari buku-buku suci, berjapa suku kata suci A-U-M (Om) dan penilaian diri.

e. Isvarapranidhana: penyerahan dan pengabdian kepada Tuhan.

Konsep Yama dan Nyama merupakan sebuah ajaran etika/moral. Pendidikan karakter sangat bergantung pada penanaman etika yang baik, hal ini dapat dilihat dari tingkah laku keseharian siswa disekolah. Di SMP Nasional Denpasar, implementasi dari ajaran Yama dan Nyama dapat dilihat dari keseharian siswa, baik sebelum proses pembelajaran, pada saat proses pembelajaran, dan sesudah proses pembelajaran. Etika yang baik dapat dilihat dari sikap spiritual ataupun sikap sosial dari peserta didik.

3. Asana artinya melakukan gerakan tubuh tertentu (sesuai petunjuk yoga asana), untuk menjaga kebugaran dan kesehatan tubuh, dan membangkitkan cakra-cakra dalam diri.

4. Pranayama artinya melaksanakan latihan pernafasan yaitu: menghirup, menahan, dan mengeluarkan nafas secara teratur.

Konsep pelaksanaan dari asanas dan pranayama merupakan sebuah teknik latihan fisik. Ajaran yoga dapat meningkatkan kreatifitas siswa, yang dimana kreatifitas ini merupakan bagian alami dari suatu proses belajar yang terkait dengan inovasi. Postur-postur dan kisah-kisah yoga mampu membangkitkan daya imajinasi anak, dan mengajak siswa untuk secara kreatif memikirkan kisah tersebut. Yoga mendorong siswa untuk membentuk hubungan yang positif dan sehat dengan tubuh mereka. Yoga juga mengajarkan siswa cara-cara praktis untuk merawat diri dan membuat kebiasaan-kebiasaan yang baik bagi fisiknya. Seperti yang terdapat pada saat pembelajaran ekstrakulikuler di SMP Nasional Denpasar sebagai pada gambar di bawah ini: 

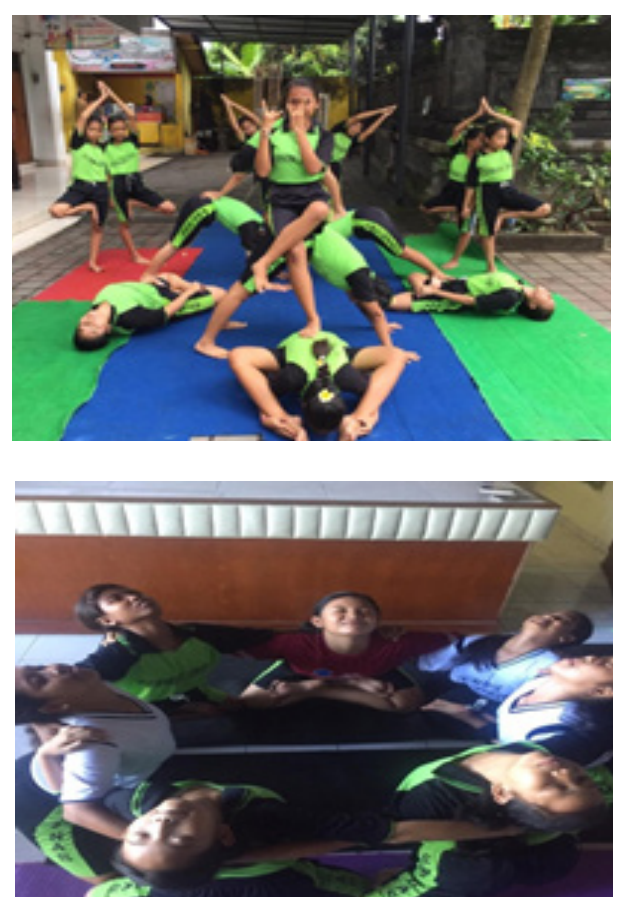

Pelaksanaan ajaran Yoga Asanas sebagai bagian dari Astangga Yoga di SMP Nasional Denpasar

5. Pratyahara artinya penarikan indria-indria dari objek-objek yang mempengaruhi keinginan kita.

6. Dharana artinya memfokuskan pikiran pada objek intra organik, atau ekstra-organik pada ujung hidung atau bulan sebagai objek.

7. Dhyana artinya melakukan kontemplasi mendalam pada suatu objek yang dilakukan secara terus-menerus.

8. Samadhi artinya melakukan konsentrasi hingga sampai pada suatu kondisi puncak, kesadaran kontemplasi hilang dari objekobjek yang dijadikan sebagai media kontemplasi dan tidak memiliki kesadaran diri sendiri.

Konsep ajaran Pratyahara sampai dengan Samadhi merupakan proses pelatihan secara mental dan juga spiritual. Ajaran ini menekankan bagaimana pengendalian diri yang harus dilaksanakan oleh peserta didik sebelum proses pembelajaran dimulai, segala emosi agar dikendalikan, baik dengan menggunakan teknik pengaturan nafas maupun menitik beratkan pada konsentrasi pada satu objek, sehingga nantinya dapat memberikan proses ketenangan dalam belajar mengajar, sebagai berikut:
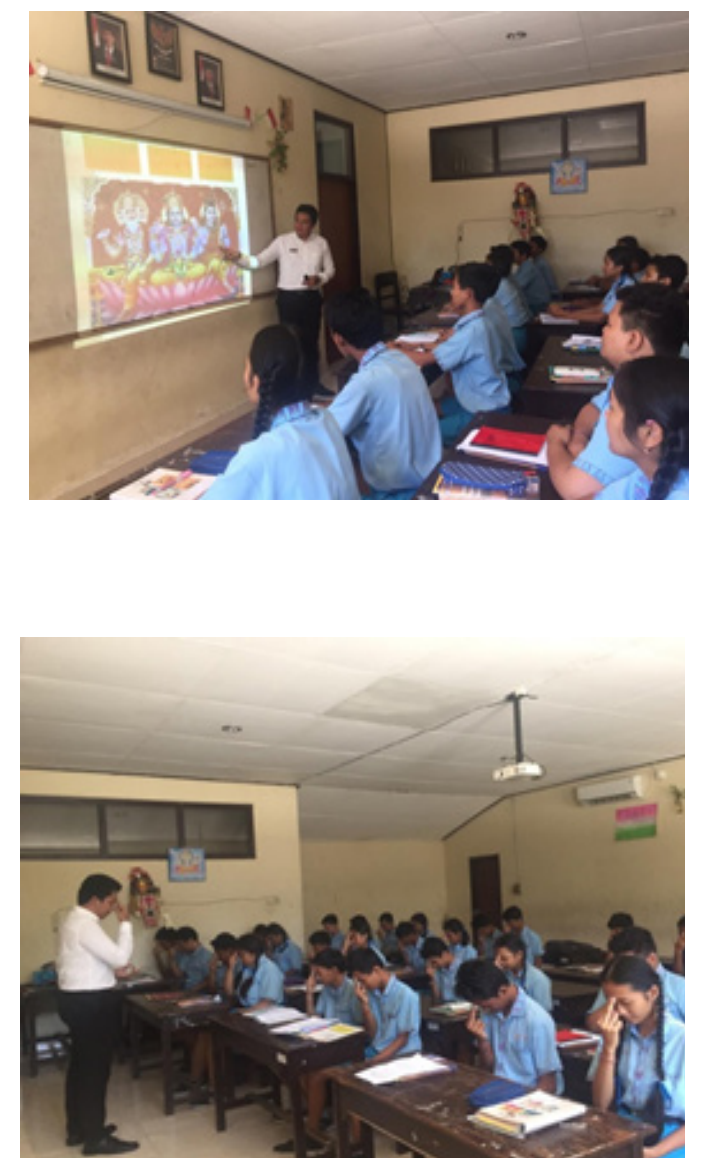

Pratyahara sebagai pengendalian pikiran pada satu objek, dan teknik nadhi sodhanam

Teknik yoga dapat meningkatkan kesadaran emosi dan membantu siswa untuk meresponnya secara efektif. Yoga mengajarkan kesadaran akan diri, cara mengatur dan menyeimbangkan diri, serta dapat menurunkan tingkat stress pada siswa. Yoga juga memupuk intelejensi emosional siswa saat mereka belajar untuk mendengarkan intuisi mereka ketika dihadapkan pada situasi yang rumit. Yoga juga dapat memberikan pengajaran pada siswa untuk mengendalikan emosi diri mereka guna membangun hubungan yang baik dengan orang disekitarnya. Ajaran yoga bermanfaat bagi siswa untuk memahami potensi diri mereka guna menyadari makna keberhasilan dan rasa 
puas bagi mereka. Sebuah penyadaran diri akan muncul dalam diri siswa mengingat ajaran yoga selalu diterapkan ketika awal mulai suatu proses pembelajaran, sehingga menyebabkan adanya perubahan perilaku dan konsentrasi belajar pada peserta didik khususnya di SMP Nasional Denpasar, sehingga ketika melaksanakan teknik Pratyahara-Samadhi (meditasi) dapat kita tanamkan nilai-nilai karakter yang harus ada dalam peserta didik, dan juga harus dilaksanakan dalam kesgiatan sehari-hari. Maka dari itu, proses pendidikan karakter berupa penyadaran diri secara spiritual akan terwujud dengan baik.

\section{PENUTUP}

Pendidikan merupakan wahana pengubahan kepribadian dan pengembangan diri. Pendidikan karakter bisa dikatakan sebagai sebuah usaha untuk menghidupkan spiritual dan mental. Penanaman nilai spiritual dan mental menjadi sangat penting untuk dapat mendukung proses pendidikan karakter tersebut. Proses pendidikan yang menitikberatkan pada spiritual dan mental tentunya terdapat dalam konsep agama Hindu yakni ajaran yoga. Ajaran yoga yang dimaksud adalah Astangga Yoga dari Maharsi Patanjali yang terdiri dari; yama $=$ pengendalian, nyama $=$ sikap moral, asana $=$ sikap tubuh, pranayama $=$ pengaturan nafas, pratyahara $=$ penarikan indriaindria, dharana $=$ atensi, dhyana $=$ meditasi, Samadhi $=$ konsentrasi. Ajaran Astangga Yoga tersebut sangat menitik beratkan pada pendidikan karakter, Etika dalam beryoga diwujudkan oleh yama dan nyama sebagai sebuah pengendalian diri. asana dan pranayama merupakan sebuah pengendalian fisik, sedangkan pratyahara, dharana, dhyana, dan Samadhi merupakan sebuah pelatiah secara mental dan spiritual. SMP Nasional Denpasar sudah melaksanakan proses ajaran Astangga Yoga sebagai sebuah penguatan pendidikan karakter. Adanya ekstrakulikuler yoga sebagai sebuah tahapan latihan fisik bagi peserta didik, dan proses konsentrasi dan pengendalian diri serta emosi, sudah dilaksanakan pada awal proses pembelajaran di kelas pada saat pelajaran agama Hindu dan Budi Pekerti, yang memiliki manfaat untuk dapat mengendalikan emosi dan ego pada peserta didik, sehingga proses pembelajaran dapat berlangsung dengan nyaman.

\section{DAFTAR PUSTAKA}

https://id.m.wikipedia.org/wiki/Pendidikan karakter.

Departemen Pendidikan Nasional. 2003. UndangUndang RI No. 20 Tahun 2003. Tentang Sistem Pendidikan Nasional.

Kajeng, I Nyoman, dkk. 1997. Sarasamuccaya. Surabaya: Paramitha.

Seregig, I Ketut. 2012. Nawa Darsana 9 sistem filsafat Hindu. Surabaya: Paramitha.

Donder, I Ketut, dan I Ketut Wisarja. 2011. Teologi Sosial. Surabaya: Paramitha.

Widya, Setta. 2015. Panduan Dasar Yoga. Jakarta: PT. Kawan Pustaka 